\title{
Sludge disintegration model with finite disintegration rate
}

\author{
F. S. Al Saadi ${ }^{1} \quad$ M. I. Nelson ${ }^{2} \quad$ A. L. Worthy ${ }^{3}$
}

(Received 22 December 2015; revised 27 October 2016)

\begin{abstract}
The activated sludge process is the most widely used biological wastewater treatment method for domestic and industrial wastewaters. One drawback of this process is the production of 'sludge'. The expense for treating excess sludge accounts for 50-60\% of the operating costs in a wastewater treatment plant. Traditional methods for disposing of excess sludge are increasingly regulated due to environmental concerns about the presence of potentially toxic elements in the sewage sludge. A promising method to reduce excess sludge production is to increase its biodegradability by disintegrating it within the bioreactor. We extend an earlier model by allowing the sludge disintegration reactions to occur at a finite rate. Furthermore, we include a more realistic model for the hydrolysis of particulate matter by allowing the rate of
\end{abstract}

DOI:10.21914/anziamj.v57i0.10385, (C) Austral. Mathematical Soc. 2016. Published November 18, 2016, as part of the Proceedings of the 12th Biennial Engineering Mathematics and Applications Conference. ISSN 1445-8810. (Print two pages per sheet of paper.) Copies of this article must not be made otherwise available on the internet; instead link directly to the DOI for this article. Record comments on this article via http://journal . austms . org. au/ojs/index.php/ANZIAMJ/comment/add/10385/0 
hydrolysis to saturate at high particulate concentrations. We analyze the steady-state operation of an activated sludge system incorporating a sludge disintegration unit to prevent excess sludge production.

\section{Contents}

1 Introduction

C347

2 Equations

C350

2.1 Biochemical processes . . . . . . . . . . . . . C C350

2.2 Finite rate sludge disintegration model . . . . . . . . . C C351

2.3 The dimensional model . . . . . . . . . . . . . . . . C351

2.4 The dimensionless model . . . . . . . . . . . . . . . C354

3 Discussion

C355

3.1 Zero excess sludge production . . . . . . . . . . C357

3.2 Finite rate kinetics . . . . . . . . . . . . . . . . C358

4 Conclusion

C360

References

C361

A Kinetic and stoichiometric parameter values

C363

\section{Introduction}

The activated sludge process is widely used to treat wastewater that is high in biodegradable organic components. The treated wastewaters may originate in the domestic and/or industrial sectors [11]. The essence of the process is the use of microorganisms in the reactor which consume organic pollutants (substrate) to produce more microorganisms, in the process transforming the 
substrates into a variety of chemicals. A major disadvantage of the activated sludge process is the production of extra sludge. Disposal of this sludge was found to be approximately $50-60 \%$ of the total operating costs in a wastewater treatment plant $[3,5]$.

There are three broad methods for the disposal of sludge: incineration, landfill sites, and dumping at sea. However, these methods are becoming increasingly regulated worldwide due to environmental concerns about the presence of potentially toxic elements, and costs that include both transportation and available land sites [7]. Thus it is increasingly important to explore ways that decrease the volume and mass of excess sludge produced as part of biological wastewater treatment processes. The reduction of excess sludge production can be achieved by increasing sludge biodegradability by disintegrating it within the reactor. In this method, the bioreactor is attached to a sludge disintegrator unit which disintegrates the sludge and returns the liquefied sludge back to the bioreactor [13]. There are several sludge disintegration methods such as: enzyme treatment [2], the addition of anoxic/anaerobic stages [13], freezing and thawing [4], ultrasound [14], ozonation [5, 10, 12] and ozonation combined with chemical treatment [9].

Of the numerous techniques used to decrease sludge production, chemical and ozone treatments have been extensively adopted in commercial activated sludge plants. We investigate a model for a sludge disintegration unit in which sludge removed from the bioreactor is treated by ozone. In the sludge disintegration unit the input sludge is converted to a mixture of soluble substrate and particulates. The mixture is then supplied to the reactor as a feed solution. This method was shown to lower the amount of mixed liquor suspended solids (MLSS) within the reactor. MLSS is a key component or measure in the cost effective operation of a disintegration unit.

In practice a target value for the MLSS is set. If the MLSS value is below (above) the target value, then the bioreactor is said to be operating in negative (positive) excess sludge production. If the value of MLSS is equal to the target value, then the bioreactor is said to produce zero excess sludge production. 
Yoon [13] proposed a model for a membrane bioreactor containing a sludge disintegration unit. In this model the sludge disintegration unit is not modelled per se but is represented by sludge disintegration terms that are added to a conventional activated sludge model. These terms assume that the sludge is destroyed at an infinite rate by the disintegration unit. Yoon [13] investigated the model by integrating the governing equations. Nelson and Yue [8] reinvestigated using a steady-state analysis, where many important practical features were identified for the first time. Yoon's model, developed for a membrane bioreactor, was extended by Nelson and Balakrishnan [7] to the traditional activated sludge process. Nelson and Balakrishnan [7] showed that it is possible to guarantee that the bioreactor always operates in a state of negative excess sludge production.

Alharbi et al. [1] extended the underlying biochemical model of the activated sludge process. The assumption that the disintegration processes occur instantaneously was relaxed to allow the processes to occur at a finite rate. Alharbi et al. [1] investigated how the disintegration unit can be used to govern the amount of sludge within the reactor.

We extend Yoon's [13] original model for a sludge disintegration unit attached to a membrane bioreactor. Firstly, we follow Alharbi et al. [1] by allowing the sludge disintegration kinetics to occur at a finite rate. Secondly, we modify the hydrolysis reaction term to allow it to become saturated at high concentrations of particulates. 


\section{Equations}

\subsection{Biochemical processes}

The first biochemical process is the hydrolysis of biodegradable particulate substrate $\mathrm{P}$ to produce soluble substrate $\mathrm{S}$ :

$$
\mathrm{P} \stackrel{\mathrm{k}_{\mathrm{h}}^{\prime}(\mathrm{P})}{\longrightarrow} \beta S
$$

where $\beta$ is the yield factor for hydrolysis of insoluble organic compounds and $k_{h}^{\prime}(P)$ is the hydrolysis rate. The feed into the membrane bioreactor does not contain any particulate matter, it is created in the sludge disintegration unit. The second biochemical process is the use of soluble organic materials $S$ as a substrate for energy and growth by the biomass $X$ :

$$
S \stackrel{\mu(S)}{\longrightarrow} Y X
$$

where $Y$ is the yield factor for the growth of biomass and $\mu(S)$ is the growth rate.

The final biochemical process is the death of biomass at the death rate $k_{d}$ :

$$
X \stackrel{k_{d}}{\rightarrow} \text { stuff. }
$$

The products of biomass decay are non-biodegradable particulates and slowly biodegradable particulates. The production of these decay products are not included in our model. This is a standard assumption for simplified models of the kind considered in this article. The decay products are included in more complex models, such as the activated sludge model [6].

The MLSS is important to determine the amount of sludge in the bioreactor. It is defined as

$$
\operatorname{MLSS}=\mathrm{X}+\mathrm{P} .
$$




\subsection{Finite rate sludge disintegration model}

Based upon Yoon's [13] model equations, we assume that there are two sludge disintegration processes: disintegration of particulate in the sludge disintegration unit; and disintegration of microorganism in the sludge disintegration unit.

The disintegration of particulate is described by

$$
P_{r} \stackrel{k_{p}}{\longrightarrow}\left(1-\delta_{1}\right) P_{r}+\gamma_{1} \delta_{1} S_{r} .
$$

where $k_{p}$ is the finite rate at which particulate substrate is disintegrated, $\delta_{1}$ is the fraction of the particulate substrate that is converted into soluble substrate, and $\gamma_{1}$ is the conversion efficiency from particulate substrate to soluble substrate. (If the units of particulate and soluble substrate were identical, then $\left.\gamma_{1}=1\right)$.

The disintegration of microorganism is

$$
X_{r} \stackrel{k_{x}}{\rightarrow}\left(1-\delta_{2}\right) P_{r}+\gamma_{2} \delta_{2} S_{r}
$$

where $k_{x}$ is the finite rate at which microorganisms are disintegrated, $\delta_{2}$ is the fraction of the microorganisms that are converted into soluble substrate, and $\gamma_{2}$ is the conversion efficiency from microorganisms to soluble substrate. (If the units of microorganisms and soluble substrate were identical, then $\left.\gamma_{2}=1\right)$. Conservation of mass requires that

$$
\alpha\left[\gamma_{2} \delta_{2}+\gamma_{1} \delta_{1}\left(1-\delta_{2}\right)\right]<1, \quad \alpha\left[\gamma_{2} \delta_{2}+\gamma_{2}\left(1-\delta_{2}\right)\right]<1 .
$$

\subsection{The dimensional model}

We present the model equations for a membrane bioreactor coupled to a sludge disintegration unit in which the disintegration processes occur at a 
finite rate. Table 1 defines the parameters in equations (6)-(13). Appendix A gives typical values of some parameters, as given by Yoon [13].

The membrane bioreactor model is

$$
\begin{aligned}
& V \frac{d S}{d t}=F\left(S_{0}-S\right)-V X \frac{\mu(S)}{Y}+F D\left(S_{r}-S\right)+V \beta k_{h}^{\prime}(P), \\
& V \frac{d X}{d t}=V X \mu(S)+F D\left(X_{r}-X\right)-V k_{d} X \\
& V \frac{d P}{d t}=-V k_{h}^{\prime}(P)+F D\left(P_{r}-P\right) .
\end{aligned}
$$

The specific growth rate is

$$
\mu(S)=\mu_{m} \frac{S}{K_{s}+S} .
$$

The maximum hydrolysis rate of particulate is

$$
k_{h}^{\prime}(P)=k_{h} \frac{P}{K_{s p}+P} .
$$

We assume that the finite rates at which the disintegration processes occur are much quicker than those of the biochemical processes. Consequently, none of the biochemical processes that occur within the membrane reactor are included in the disintegration unit model. The sludge disintegration unit model is

$$
\begin{aligned}
& V_{s} \frac{d S_{r}}{d t}=F D\left(S-S_{r}\right)+V_{s} \delta_{1} \gamma_{1} k_{p} P_{r}+V_{s} \delta_{2} \gamma_{2} k_{x} X_{r}, \\
& V_{s} \frac{d X_{r}}{d t}=F D\left(X-X_{r}\right)-V_{s} k_{x} X_{r}, \\
& V_{s} \frac{d P_{r}}{d t}=F D\left(P-P_{r}\right)+V_{s} \delta_{1} k_{p} P_{r}-\left(1-\delta_{2}\right) V_{s} k_{x} X_{r} .
\end{aligned}
$$


Table 1: Nomenclature for equations (6)-(13).

\begin{tabular}{|c|c|c|}
\hline Param. & Description & units \\
\hline $\mathrm{D}$ & Sludge disintegration factor & \\
\hline $\mathrm{F}$ & Flowrate through the bioreactor & $\mathrm{dm}^{3} \mathrm{hr}^{-1}$ \\
\hline $\mathrm{K}_{\mathrm{s}}$ & Monod constant & $|\mathrm{S}|$ \\
\hline$K_{s p}$ & Monod constant in the hydrolysis function & $|\mathrm{P}|$ \\
\hline$P$ & Concentration of particulates & $|X|$ \\
\hline$P_{r}$ & $\begin{array}{l}\text { Concentration of particulates in sludge } \\
\text { disintegration unit }\end{array}$ & $|X|$ \\
\hline $\mathrm{S}_{0}$ & Substrate concentration in the feed & $|S|$ \\
\hline$S_{r}$ & $\begin{array}{l}\text { Substrate concentration in the sludge disinte- } \\
\text { gration unit }\end{array}$ & $|S|$ \\
\hline V & Bioreactor volume & $\mathrm{dm}^{3}$ \\
\hline$V_{s}$ & Volume of the sludge disintegration unit & $\mathrm{dm}^{3}$ \\
\hline$x_{r}$ & $\begin{array}{l}\text { Concentration of biomass in the sludge disin- } \\
\text { tegration unit }\end{array}$ & $|X|$ \\
\hline Y & Yield factor & $|X||S|^{-1}$ \\
\hline$k_{d}$ & Sludge decay rate constant & $\mathrm{hr}^{-1}$ \\
\hline$k_{h}$ & Maximum hydrolysis rate of particulates & $|\mathrm{X}| \mathrm{hr}^{-1}$ \\
\hline$k_{p}$ & Particulates disintegration rate & $\mathrm{hr}^{-1}$ \\
\hline$k_{x}$ & Biomass disintegration rate & $\mathrm{hr}^{-1}$ \\
\hline $\mathrm{t}$ & Time & hr \\
\hline$k_{h}^{\prime}$ & Rate of hydrolysis & $|\mathrm{X}| \mathrm{hr}^{-1}$ \\
\hline$\beta$ & $\begin{array}{l}\text { Conversion efficiency from non-biodegradable } \\
\text { particulates to biodegradable substrate }\end{array}$ & $|S||X|^{-1}$ \\
\hline$\gamma_{1}$ & $\begin{array}{l}\text { Conversion efficiency from particulate sub- } \\
\text { strate to soluble substrate }\end{array}$ & $|S||X|^{-1}$ \\
\hline$\gamma_{2}$ & $\begin{array}{l}\text { Conversion efficiency from biomass to soluble } \\
\text { substrate }\end{array}$ & $|S||X|^{-1}$ \\
\hline$\delta_{1}$ & $\begin{array}{l}\text { Fraction of particulate substrate converted to } \\
\text { soluble substrate }\end{array}$ & \\
\hline
\end{tabular}


$\delta_{2} \quad$ Fraction of biomass converted to soluble substrate

$\begin{array}{lll}\mu(S) & \text { Specific growth rate model } & \mathrm{hr}^{-1} \\ \mu_{\mathrm{m}} & \text { Maximum specific growth rate } & \mathrm{hr}^{-1} \\ \tau=\mathrm{V} / \mathrm{F} & \text { Residence time } & \mathrm{hr}\end{array}$

\subsection{The dimensionless model}

Dimensionless variables are defined for the substrate $S^{*}=S / K_{s}$, cell mass $\mathrm{X}^{*}=\mathrm{X} / \mathrm{YK}_{\mathrm{s}}$, and particulate concentration $\mathrm{P}^{*}=\mathrm{P} / \mathrm{YK}_{\mathrm{s}}$ in the bioreactor. Similarly, dimensionless variables are defined for the substrate $S_{r}^{*}=S_{r} / K_{s}$, cell mass $\mathrm{X}_{\mathrm{r}}^{*}=\mathrm{X}_{\mathrm{r}} / \mathrm{YK}_{\mathrm{s}}$, and particulate concentration $\mathrm{P}_{\mathrm{r}}^{*}=\mathrm{P}_{\mathrm{r}} / \mathrm{YK}_{\mathrm{s}}$ in the sludge disintegration unit. In addition, for nondimensional time $t^{*}=\mu_{\mathrm{m}} t$, the dimensional model equations (14)-(19) in dimensionless form are

$$
\begin{aligned}
\frac{d S^{*}}{d t^{*}} & =\frac{S_{0}^{*}-S^{*}}{\tau^{*}}-\frac{X^{*} S^{*}}{1+S^{*}}+\frac{1}{\tau^{*}} D\left(S_{r}^{*}-S^{*}\right)+\beta^{*} \frac{k_{h}^{*} P^{*}}{K_{s p}^{*}+P^{*}} \\
\frac{d X^{*}}{d t^{*}} & =\frac{X^{*} S^{*}}{1+S^{*}}+\frac{1}{\tau^{*}} D\left(X_{r}^{*}-X^{*}\right)-k_{d}^{*} X^{*} \\
\frac{d P^{*}}{d t^{*}} & =-k_{h}^{*} \frac{P^{*}}{K_{s p}^{*}+P^{*}}+\frac{1}{\tau^{*}} D\left(P_{r}^{*}-P^{*}\right), \\
\frac{d S_{r}^{*}}{d t^{*}} & =\frac{D V^{*}}{\tau^{*}}\left(S^{*}-S_{r}^{*}\right)+\delta_{1} \gamma_{1}^{*} k_{\mathrm{p}}^{*} P_{r}^{*}+\delta_{2} \gamma_{2}^{*} k_{x}^{*} X_{r}^{*} \\
\frac{d X_{r}^{*}}{d t^{*}} & =\frac{D V^{*}}{\tau^{*}}\left(X^{*}-X_{r}^{*}\right)-k_{x}^{*} X_{r}^{*} \\
\frac{d P_{r}^{*}}{d t^{*}} & =\frac{D V^{*}}{\tau^{*}}\left(P^{*}-P_{r}^{*}\right)-\delta_{1} k_{p}^{*} P_{r}^{*}+\left(1-\delta_{2}\right) k_{x}^{*} X_{r}^{*}
\end{aligned}
$$

Table 2 describes some dimensionless parameters. Henceforth we assume that the disintegration rate of biomass $k_{x}^{*}$ is equal to the disintegration rate of particulates $k_{\mathrm{p}}^{*}$, with $k_{\mathrm{p}}^{*}=k_{\mathrm{x}}^{*}=\mathrm{k}^{*}$. 
Table 2: Dimensionless nomenclature for equations (14)-(19). Param.

Description

\begin{tabular}{ll}
\hline $\mathrm{K}_{\mathrm{sp}}^{*}=\mathrm{K}_{\mathrm{sp}} /\left(\mathrm{YK}_{\mathrm{s}}\right)$ & Monod constant in the hydrolysis function \\
$\mathrm{S}_{0}^{*}=\mathrm{S}_{0} / \mathrm{K}_{\mathrm{s}}$ & Substrate concentration in the feed \\
$\mathrm{V}^{*}=\mathrm{V} / \mathrm{V}_{\mathrm{s}}$ & Reciprocal of the scaled SDU reactor volume \\
$\mathrm{k}_{\mathrm{d}}^{*}=\mathrm{k}_{\mathrm{d}} / \mu_{\mathrm{m}}$ & Death coefficient \\
$\mathrm{k}_{\mathrm{h}}^{*}=\mathrm{k}_{\mathrm{h}} /\left(\mathrm{YK}_{\mathrm{s}} \mu_{\max }\right)$ & The maximum hydrolysis rate of the particu- \\
& lates \\
$\mathrm{k}_{\mathrm{p}}^{*}=\mathrm{k}_{\mathrm{p}}^{*} / \mu_{\max }$ & Rate at which particulate substrate is disin- \\
$\mathrm{k}_{\mathrm{x}}^{*}=\mathrm{k}_{\mathrm{x}} / \mu_{\max }$ & tegrated \\
$\mathrm{t}^{*}=\mu_{\mathrm{m}} \mathrm{t}$ & The rate at which biomass is disintegrated \\
$\beta^{*}=\beta \mathrm{Y}$ & Time \\
$\gamma_{1}^{*}=\mathrm{Y} \gamma_{1}$ & Conversion efficiency from non-biodegradable \\
$\gamma_{2}^{*}=\mathrm{Y} \gamma_{2}$ & Conversion efficiency from particulate sub- \\
$\tau^{*}=\mathrm{V} \mu_{\mathrm{m}} / \mathrm{F}$ & strate to soluble substrate \\
& Conversion efficiency from biomass
\end{tabular}

\section{Discussion}

In this section we study conditions for achieving a target value of the MLSS (or zero exess sludge production) under normal operation of the bioreactor. From experimental data, the MLSS target value is set to $12 \mathrm{~g} \mathrm{~L}^{-1}$ [13] which converts to a target dimensionless value $\mathrm{MLSS}_{\text {target }}^{*}=240$.

The steady-state solutions of equations (14)-(19) were found numerically using the solve command in Maple. Only solutions where all components are non-negative are physically meaningful. The stabilites of the physically meaningful solutions were determined numerically. In our figures only the stable physically meaningful solutions are plotted. Figure 1 shows the MLSS 
Figure 1: Steady state diagram for the dimensionless mixed liquor suspended solid concentration MLSS* inside a membrane bioreactor as a function of the dimensionless residence time $\tau^{*}$. The horizontal line is the target value MLSS target $^{*}$.

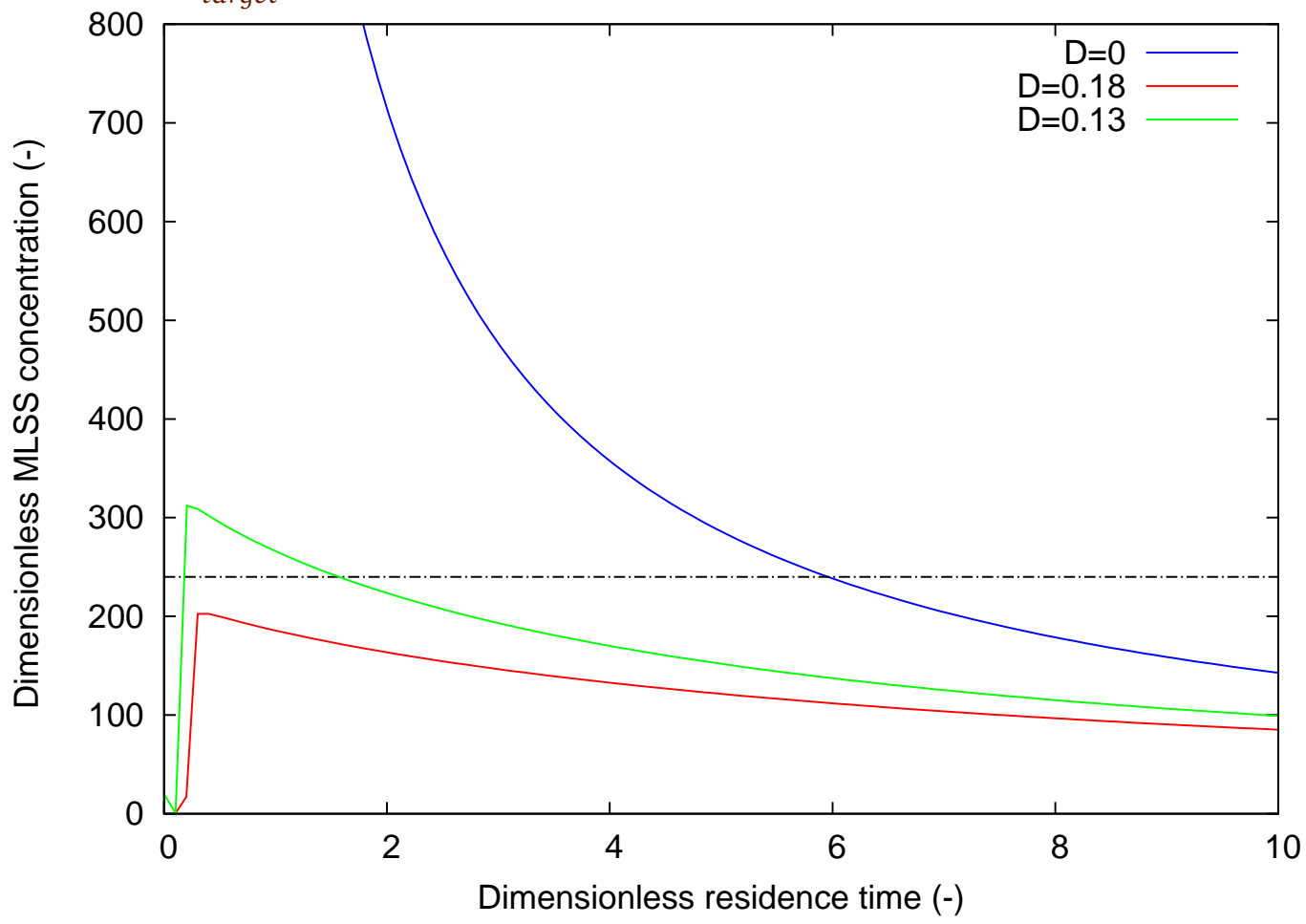

steady state curve against the residence time $\tau$. The horizontal line represents the scaled target value. When the sludge disintegration unit is turned off $(\mathrm{D}=0)$ there is one intersection point at $\tau=6$. For values of the residence time $\tau<6$, the bioreactor is in a state of positive sludge production. Sooner or later the bioreactor must be turned off and the excess sludge disposed off. For values of the residence time greater than the value intersection value, $\tau>6$, the bioreactor is in a state of negative excess sludge production. 
Figure 1 shows that when $\mathrm{D}=0.13$ the MLSS steady state curve intersects the MLSS target value twice. Thus there are two residence times, $\tau=\tau_{1}^{*} \approx 0.15$ and $\tau=\tau_{2}^{*} \approx 1.615$, when the bioreactor is operating in a state of zero excess sludge production. If the residence time is smaller than $\tau_{1}^{*}$ or larger than $\tau_{2}^{*}$, then the bioreactor operates in a state of negative excess sludge production. Only residence times larger than $\tau_{2}^{*}$ are of operational interest because when the residence time is smaller than $\tau_{1}^{*}$ the effluent concentration is higher. When the residence time lies in between $\tau_{1}^{*}$ and $\tau_{2}^{*}$ the bioreactor is in a state of positive excess sludge production.

When the value of the sludge disintegration factor is increased to $D=0.18$ then the maximum value of the MLSS steady state curve, MLSS $_{\max }=225.9$, is below the target value. Thus for any value of the residence time the system is in a state of negative excess sludge production.

From Figure 1 we anticipate that there is a critical value for the disintegration factor $\mathrm{D}$ at which the maximum value of the dimensionless MLSS concentration is equal to the target value. For values of the sludge disintegration factor greater than this value the bioreactor will operate in a state of negative excess sludge production for any value of the residence time.

\subsection{Zero excess sludge production}

In order to investigate the critical value of the sludge disintegration factor Figure 2 plots the value of the residence time at which there is zero excess sludge production as a function of the sludge disintegration factor.

When the sludge disintegration factor is zero there is one value of the residence time for zero excess sludge production. When the sludge disintegration factor is larger than zero but smaller than the critical value, $0<\mathrm{D}<\mathrm{D}_{\mathrm{cr}}$, there are two values of the residence time for zero excess sludge production. When the sludge disintegration factor is equal to the critical value there is one value of the residence time for zero excess sludge production. When the sludge 
Figure 2: The zero excess sludge production curve as a function of the sludge disintegration rate $\mathrm{D}$ and dimensionless residence time $\tau^{*}$. The red circle indicates the critical value for the sludge disintegration rate $D_{c r}$.

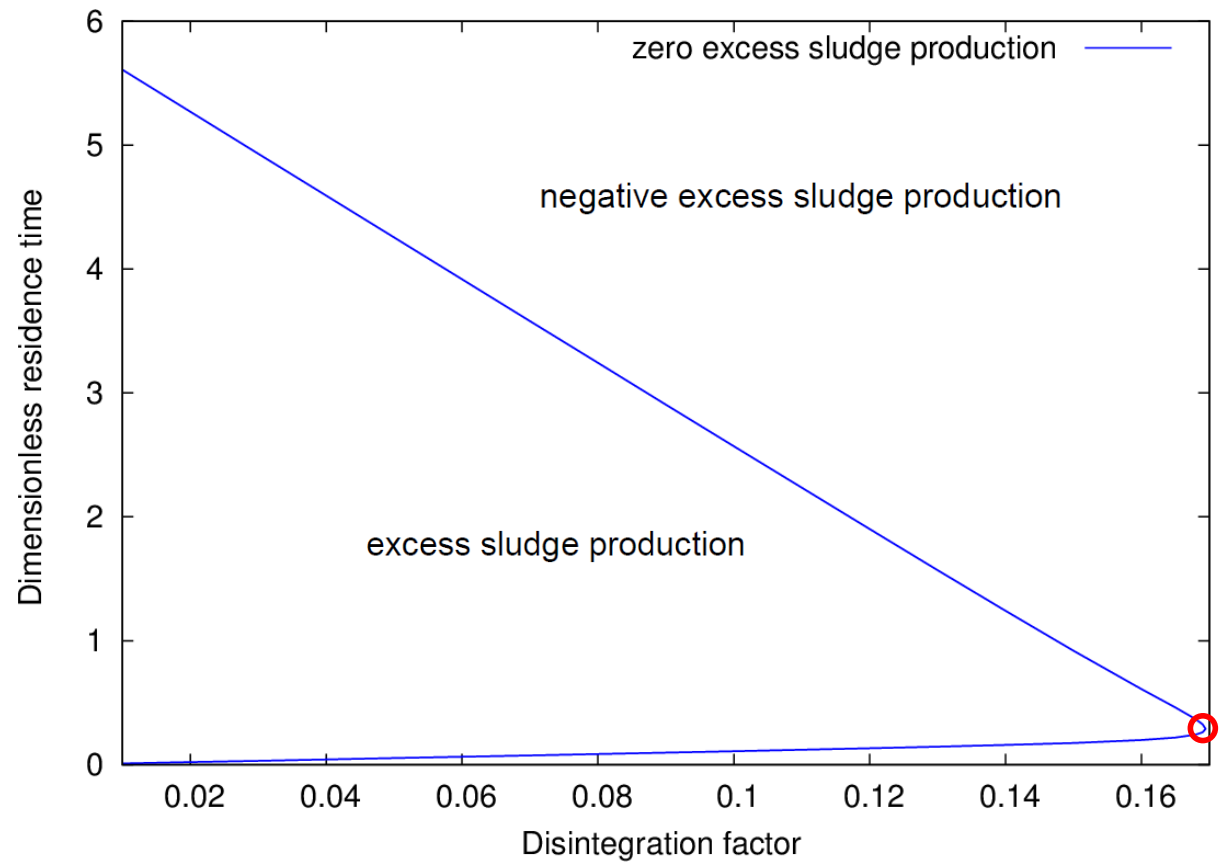

disintegration factor is larger than the critical value then there are no values for the residence time for zero excess sludge production. The parameter values at the critical point are $\mathrm{D}_{\mathrm{cr}} \approx 0.1694$ and $\tau_{1}^{*}=\tau_{2}^{*} \approx 0.2882$.

\subsection{Finite rate kinetics}

In this section, we examine how the critical value of $\mathrm{D}$ depends upon the value of the disintegration rate $k_{p}^{*}=k_{x}^{*}=k^{*}$. Figure 3 shows the relevant unfolding diagram. For a fixed value of the disintegration rate, if the value of the sludge disintegration factor is greater than the critical value, then on the 
Figure 3: The critical value of the sludge disintegration rate $\mathrm{D}_{\text {cr }}$ as a function of the dimensionless disintegration rate $k^{*}$.

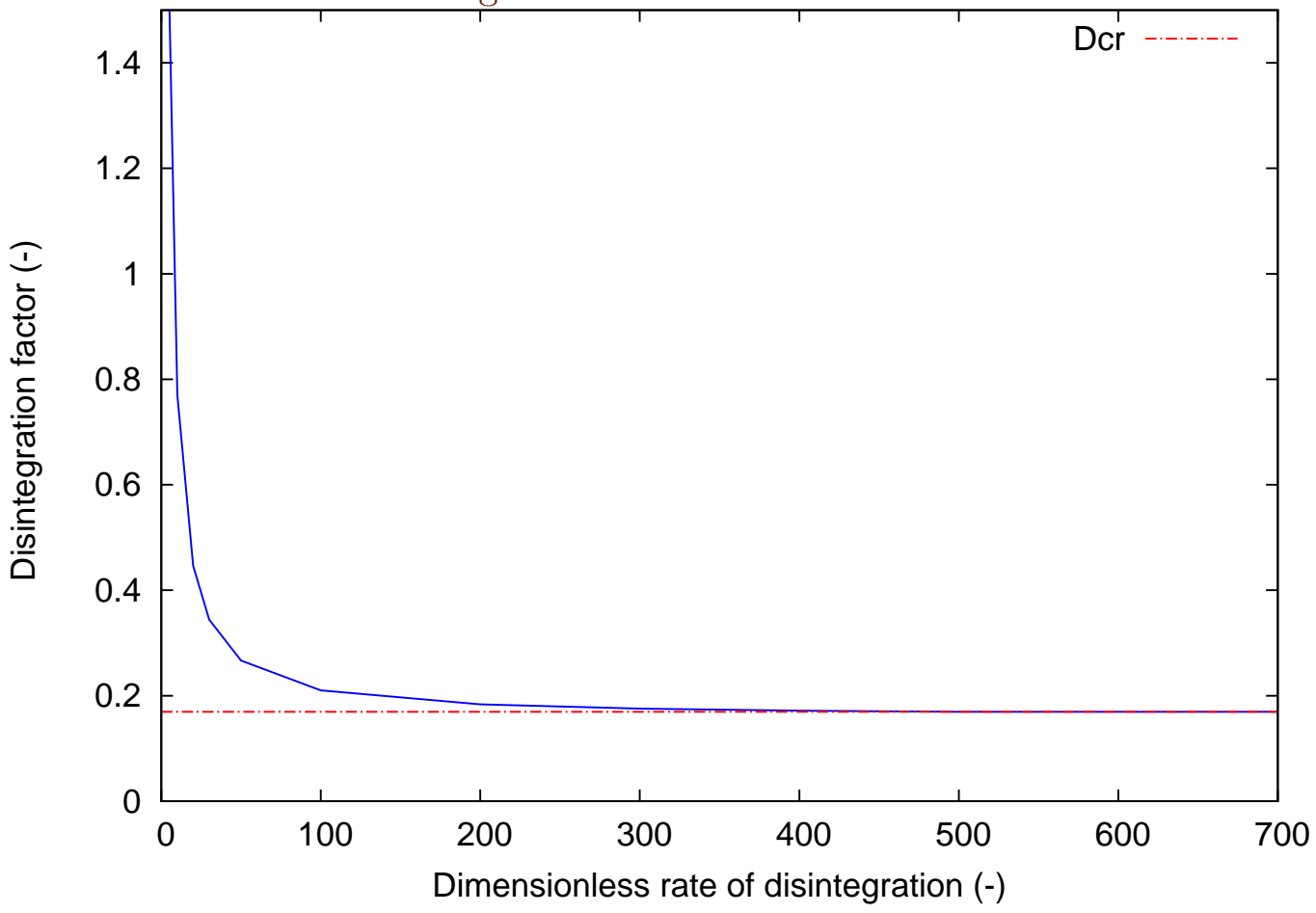

corresponding steady-state diagram the MLSS is guaranteed to be below the target value for any value of the residence time.

Figure 3 shows that the critical value of the sludge disintegration rapidly approaches its limiting value as the disintegration rate approaches infinity. This suggests that it will be profitable to analyse the model taking the limit $k^{*} \rightarrow \infty$. As the disintegration rate is reduced towards zero, the critical value of the disintegration factor increases rapidly. The submodel for the sludge disintegration unit ceases to be valid when $k^{*} \approx 1$ since here the assumption that sludge disintegration is much quicker than the biochemical processes begins to break down. At the limit value of the sludge disintegration 
the biochemical processes must be included within the sludge disintegration unit. However, from a practical perspective this limit is not of interest; if the timescale for sludge disintegration was similar to that of the biochemical processes, then it would cease to be an effective mechanism for removing sludge.

\section{Conclusion}

We revisited Yoon's model for a sludge disintegration unit attached to a membrane bioreactor [13]. We extended this model in two ways. Firstly, we allowed the sludge disintegration kinetics to be of finite rate rather than infinite. Secondly, we modified the hydrolysis function to allow it to saturate at high particulate concentrations.

We investigated the steady-state mixed liquour suspended solids (MLSS) content of the bioreactor as a function of process parameters. We showed that there is a critical value of the sludge disintegration factor $D$. If the value of the sludge disintegration factor is lower than the critical value, then there is a range of values of the residence time over which the bioreactor will operate in a state of excess sludge production. This is undesirable because eventually the reactor must be halted and the sludge disposed. If the value of the sludge disintegration factor is higher than the critical value, then the bioreactor is guaranteed to be in a state of negative sludge production; that is, the steady-state MLSS value is always below the target value for any value of the residence time. Negative sludge production is highly desirable in practice.

We investigated how the critical value of the MLSS depends upon the rate $k^{*}$ at which the sludge disintegration processes occur. This analysis suggested that it will be insightful to carry out a steady-state analysis in which the disintegration rate is treated as an asymptotic parameter. 
Acknowledgement This work was supported by the Military Technological College, Muscat Oman.

\section{References}

[1] A. Alharbi, M. I. Nelson, A. L. Worthy and H. Sidhu. Sludge formation in the activated sludge process with a sludge disintegration unit. In M. Nelson, T. Hamilton, M. Jennings and J. Bunder, Eds, Proceedings of the 11th Biennial Engineering Mathematics and Applications Conference, EMAC-2013, ANZIAM J., 55:C348-C367, 2013. doi:10.21914/anziamj.v55i0.7803 C349

[2] P. S. Barker and P. L. Dold. Sludge production and oxygen demand in nutrient removal activated sludge systems. Water Sci. Technol., 34(5-6):43-50, 1996. doi:10.1016/0273-1223(96)00627-0 C348

[3] A. Canales, A. Pareilleux, J. L. Rols, G. Goma and A. Huyard. Decreased sludge production strategy for domestic wastewater treatment. Water Sci. Technol., 30(8):97-106, 1994. doi:10.1016/S0043-1354(03)00441-X C348

[4] C. P. Chu, W. C. Feng, B.-V. Chang, C. H. Chou, and D. J. Lee. Reduction of microbial density level in wastewater activated sludge via freezing and thawing. Water Res., 33:3532-3535, 1999. doi:10.1645/0022-3395(2002)088[0718:EOFTEO]2.0.CO;2 C348

[5] E. Egemen, J. Corpening, and N. Nirmalakhandan. Evaluation of an ozonation system for reduced waste sludge generation. Water Sci. Technol., 44(2-3):445-452, 2001. http://wst. iwaponline.com/content/44/2-3/445 C348

[6] M. Henze, C. P. L. Grady Jr, W. Gujer, G. V. R. Marais, and T. Matsuo. A general model for single-sludge wastewater treatment systems. Water Res., 21(5):505-515, 1987. doi:10.1016/0043-1354(87)90058-3 C350 
[7] M. I. Nelson and E. Balakrishnan. An analysis of an activated sludge process containing a sludge disintegration system. In F. Chan, D. Marinova, and R. S. Anderssen, Eds, 19th International Congress on Modelling and Simulation, MODSIM 2011, 331-337, 2011. http://www.mssanz.org.au/modsim2011/A3/nelson.pdf C348, C349

[8] M. I. Nelson and T. C. L. Yue. A Mathematical Analysis of a Membrane Bioreactor Containing a Sludge Disintegration System . Chem. Eng. Commun., 201(10):1384-1403, 2014. doi:10.1080/00986445.2013.809001 C349

[9] Y.-K. Oh, K.-R. Lee, K.-B. Ko, and I.-T. Yeom. Effects of chemical sludge disintegration on the performance of wastewater treatment by membrane bioreactor. Water Res., 41:2665-2671, 2007. doi:10.1016/j.watres.2007.02.028 C348

[10] Z. Wang, L. Wang, B. Z. Wang, Y. F. Jiang, and S. Liu. Bench-scale study on zero excess activated sludge production process coupled with ozonation unit in membrane bioreactor. J. Environ. Sci. Heal. A, 43(11):1325-1332, 2008. doi:10.1080/10934520802177987 C348

[11] Y. Wei, R. T. Van Houten, A. R. Borger, D. H. Eikelboom, and Y. Fan. Minimization of excess sludge production for biological wastewater treatment. Water Res., 37:4553-4467, 2003. doi:10.1016/S0043-1354(03)00441-X C347

[12] H. Yasui, K. Nakamura, S. Sakuma, M. Iwasaki, and Y. Sakai. A full-scale operation of a novel activated sludge process without excess sludge production. Water Sci. Technol., 34(3-4):395-404, 1996. doi:10.1016/0273-1223(96)00604-X C348

[13] S.-H. Yoon. Important operational parameters of membrane bioreactor-sludge disintegration (MBR-SD) system for zero excess sludge production. Water Res., 37:1921-1931, 2003. doi:10.1016/S0043-1354(02)00578-X C348, C349, C351, C352, C355, C360, C363 
[14] S.-H. Yoon, H.-S. Kim, and S. Lee. Incorporation of ultrasonic cell disintegration into a membrane bioreactor for zero sludge production. Process Biochem., 39(12):1923-1929, 2004. doi:10.1016/j.procbio.2003.09.023 C348

\section{A Kinetic and stoichiometric parameter values}

Yoon [13] provided typical values of kinetic and stoichiometric parameters appropriate for the activated sludge process. These values are $\mathrm{D} \in[0,1.25](0.5), \quad \mathrm{F}=2 \mathrm{Lday}^{-1}, \quad \mathrm{~K}_{\mathrm{s}} \in[10,200](100) \mathrm{mg} \mathrm{L}^{-1}$, $\mathrm{S}_{0}=4000 \mathrm{mg} \mathrm{L}^{-1}, \quad \mathrm{~V}=8 \mathrm{~L}, \quad \mathrm{Y}=0.5 \mathrm{mg} \operatorname{MLSS}(\mathrm{mg} \mathrm{COD})^{-1}$, $k_{\mathrm{d}}=0.028$ day $^{-1}, \quad \beta=1.2 \mathrm{mg} \mathrm{COD}\left(\mathrm{mg} \mathrm{MLSS}^{-1}\right), \quad \mu_{\mathrm{m}} \in[1,10](1)$ day $^{-1}$. Where a range of values is stated, we provide in parenthesis the standard value used for our calculations. The values of the dimensionless parameters are

$$
\begin{aligned}
& S_{0}^{*} \in[20,400](400), \quad k_{d}^{*} \in[0.0028,0.028](0.028), \\
& k_{h}^{*} \in[0.006,2.2](0.3), \quad \beta^{*}=0.6, \quad \tau^{*} \in[4,40](4) .
\end{aligned}
$$

\section{Author addresses}

1. F. S. Al Saadi, Department of System Engineering, Military Technological College, Oman.

2. M. I. Nelson, School of Mathematics and Applied Statistics, University of Wollongong, Wollongong, NSW 2522 Australia.

3. A. L. Worthy, School of Mathematics and Applied Statistics, University of Wollongong, Wollongong, NSW 2522 Australia. 